\title{
Assessment of off-site early countermeasures in the event of a LOCA in a research reactor
}

\author{
C. Pappas", A. Ikonomopoulos, A. Sfetsos, S. Andronopoulos, O. Aneziris, M. Varvayanni \\ and N. Catsaros
}

Institute of Nuclear and Radiological Sciences \& Technology, Energy and Safety, National Center for Scientific Research "DEMOKRITOS", Aghia Paraskevi, 15310 Attica, Greece.

Received: 18 March 2016 / Accepted: 25 November 2016

\begin{abstract}
Off-site early emergency management actions due to a potential release from the Greek Research Reactor-1 are assessed with the aid of a modern decision support tool. To this end, a hypothetical loss-of-coolant accident has been assumed under two distinct ventilation schemes of the reactor building. Five, site-typical, meteorological scenarios have been applied based on observed conditions that demonstrate the effects the released radioactive plume has on the surrounding urban area. The JRODOS (Java-based Real-time On-line DecisiOn Support) system has been used to calculate gamma radiation doses, estimate the affected areas and assess early countermeasures in accordance with national legislation. The results indicate that the suggested countermeasures may need to be applied only to a very limited area in a few of the considered weather scenarios.
\end{abstract}

Keywords: countermeasures / research reactor / emergency response / dose / simulation

\section{Introduction}

Should radiological or nuclear $(\mathrm{RN})$ emergencies arise, adequate emergency preparedness, management and response procedures are crucial for public safety. A detailed assessment of emergency preparedness and response (EPR) guidelines has been the work of IAEA (2002). "Their implementation is intended to minimize the consequences for people, property and the environment of any nuclear or radiological emergency" (IAEA, 2002). In the case of Greece there are national guidelines on emergency preparedness that include RN emergency preparedness regulations, plans and an organizational scheme which are supplemented by an extensive environmental radioactivity monitoring network covering the national territory (Greek Government Gazette, 2003). EPR concerns primarily power reactors (PRs) but research reactors (RRs) should be considered, as well. RRs have a lower power output than PRs but pose a potential risk as they are often located in the proximity of urban areas and IAEA has issued specific recommendations on generic procedures to be followed in case of a RN emergency in RRs (IAEA, 2011).

A crucial element of EPR is determining the practical response actions (countermeasures) to be taken for the public before, during and/or after the release. In a $\mathrm{RN}$ emergency this is dependent on the estimation of the source term. The source

\footnotetext{
* Corresponding author: chpappas@ipta.demokritos.gr
}

term, defined as "The amount and isotopic composition of material released (or postulated to be released) from a facility" (IAEA, 2007), is of major importance for the accurate determination of population exposure and the initiation of appropriate emergency response procedures. The projected source term is utilized by predictive models in order to augment the understanding of a radiological situation and help formulate an appropriate countermeasure strategy. Measurements taken during a release may be referenced or incorporated in model predictions to aid the stakeholders assess the emergency during its progress.

The present work deals with the simulation and evaluation of early countermeasures for the public residing in urban areas during a hypothetical emergency in Greek Research Reactor-1 (GRR-1) with the use of the Java-based Real-time On-line DecisiOn Support (JRODOS) system for off-site emergency management (Ievdin et al., 2010). In particular, an accidental radionuclide release has been assumed to occur as a result of a hypothetical loss-of-coolant accident (LOCA). Two release scenarios involving the state of the reactor containment building have been examined whereas five typical weather scenarios have been taken into account for the release simulation. The originality of the work presented rests in the application of a comprehensive decision support system in a RR facility located in the vicinity of an urban area. Utilizing the accident scenarios developed in an earlier study the system performed the full cycle of computations starting from radionuclide dispersion and deposition through radiation 


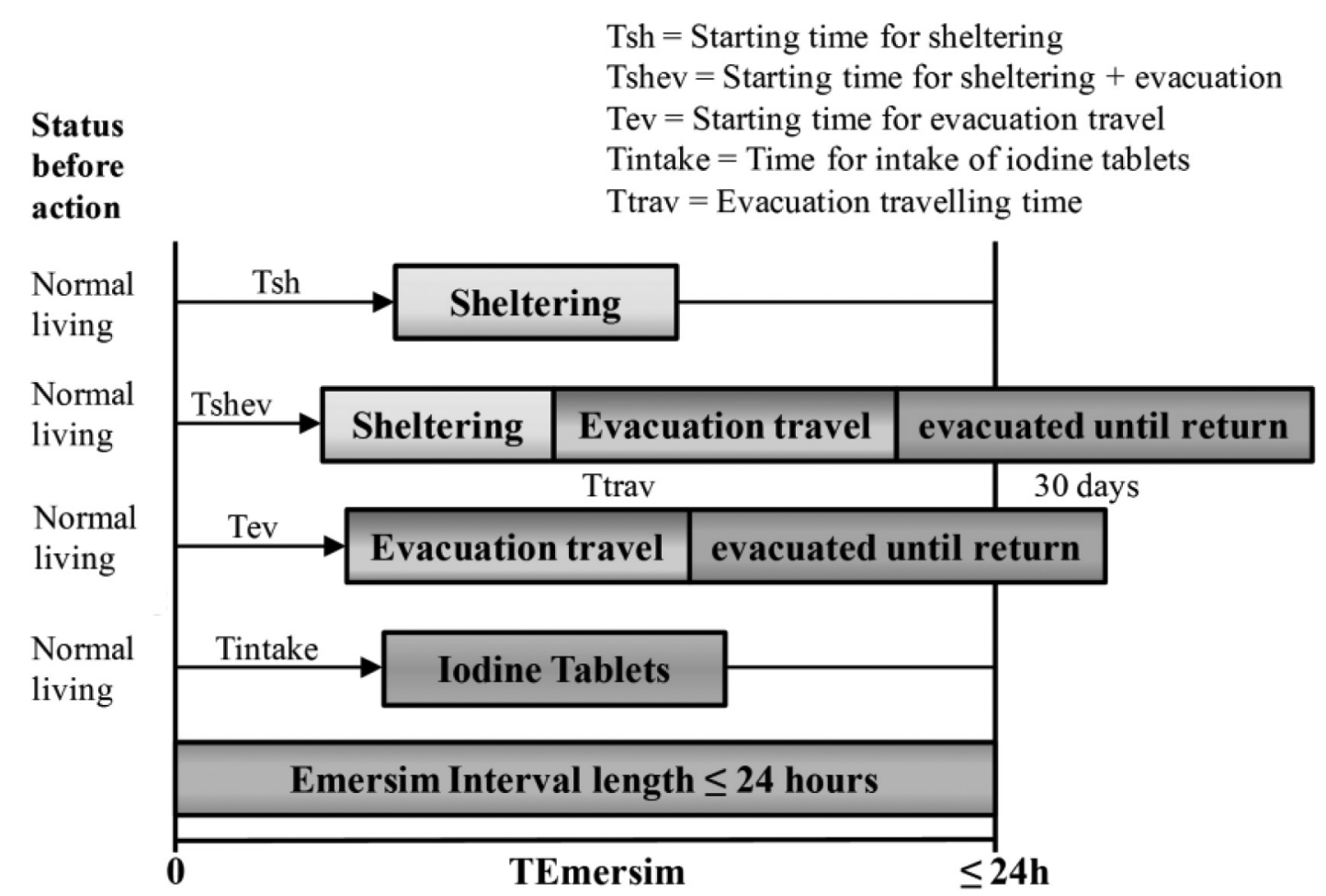

Fig. 1. Timing of emergency actions in JRODOS during TEmersim (Päsler-Sauer, 2007).

doses to proposed countermeasures. In the above framework, the next section deals with the methodology used for the simulation while the third section discusses the case study, namely the GRR-1 site, the legislation in case of nuclear emergencies and model description. The fourth section presents the results and the fifth provides the conclusions derived from the present study.

\section{Methodology for estimation of countermeasures}

JRODOS employs several countermeasure models depending on the situation (Päsler-Sauer, 2007; Charnock, 2010; Gering et al., 2010). In this study the Emergency Model Chain of the JRODOS September 2013 version has been employed. This model chain was selected as it contains the EMERSIM model (Päsler-Sauer, 2007) that simulates early countermeasures which correspond to the ones defined in the Greek national emergency plan (see Sect. 3, Fig. 2).

The countermeasures considered in EMERSIM are sheltering, evacuation, iodine intake and relocation (permanent and temporary). The criterion dose for implementation of these countermeasures in case of Greece is based on a projected dose, i.e. the dose that would be expected to be incurred if no countermeasures were to be taken (Greek Government Gazette, 2003). Thus the prognosis length determines the magnitude of the criterion dose for implementing countermeasures at locations where the criterion dose value is greater than the countermeasures intervention levels. The EMERSIM model uses a specific time period called the EMERSIM time interval (TEmersim) defined as the prognosis time during which countermeasures may be simulated. In case of a prognosis run up to $24 \mathrm{~h}$ TEmersim fully covers the entire prognosis length. Should the prognosis run be greater than $24 \mathrm{~h}$, TEmersim covers the final $24 \mathrm{~h}$ of the prognosis (PäslerSauer, 2007). Figure 1 presents the timing and duration of each of the simulated emergency actions.

\section{Case study}

\subsection{Background}

The case study involves GRR-1, a $5 \mathrm{MW}$ light water cooled and moderated - pool type reactor located within the National Center for Scientific Research "Demokritos" (NCSRD) premises in the Aghia Paraskevi suburb of Athens on the northwestern foot of Hymettus mountain. It is situated next to an inhabited urban area whereas its distance from the city center is in the order of $8 \mathrm{~km}$. The closest residence outside NCSR-D is approximately $400 \mathrm{~m}$ from the reactor building and $500 \mathrm{~m}$ from the reactor stack.

The emergency response procedures in the event of nuclear or radiological emergencies are dictated from Annex $\mathrm{R}$ "Response to emergency situations arising from significant and extended radioactive pollution due to radioactivity leakage caused by accidents in and out of Greece" of the National Emergency Plan "Xenokratis" (NEP-X) (Greek Government Gazette, 2003). Intervention levels and appropriate countermeasures defined in NEP-X are presented in Figure 2. Sheltering, evacuation and intake of iodine tablets constitute the group of considered countermeasures during a nuclear or radiological emergency. The application of a specific countermeasure depends on the magnitude of the criterion dose ( $c f$. Sect. 2) while no specific time frame for its calculation is defined in NEP-X. If the dose magnitude exceeds 


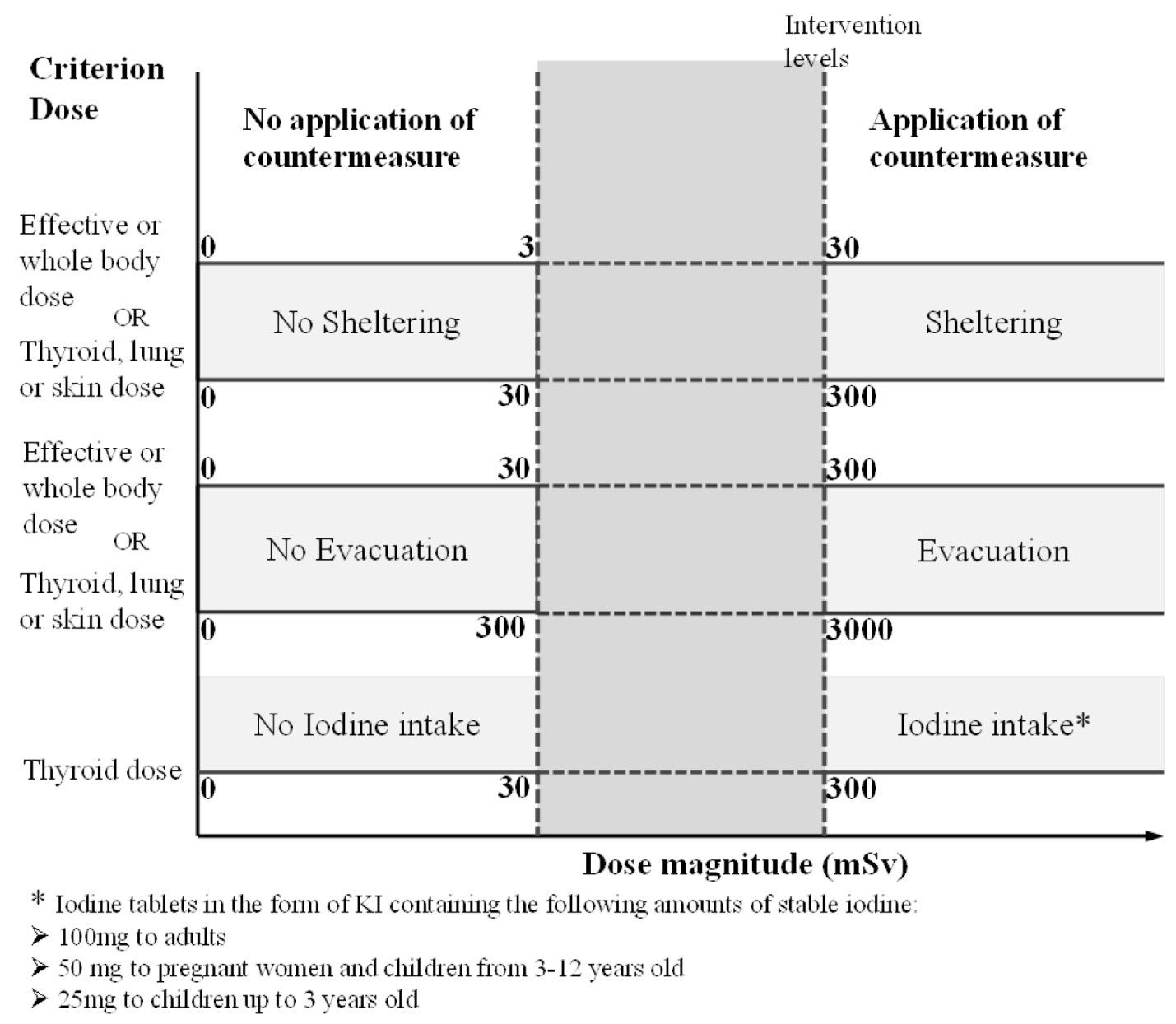

Fig. 2. Intervention levels, criterion dose and countermeasures according to Greek legislation.

the intervention levels shown in Figure 2 it is advised to put the respective countermeasure into force while the opposite is suggested if the dose magnitude lies below the lower levels. For values within the gray zone of Figure 2 a committee decides upon countermeasure implementation having taken into account the predicted or measured radionuclide dispersion and magnitude.

\subsection{Model description}

The parameters required as input to the JRODOS platform include the source term, meteorological data and countermeasure options detailed in the paragraphs that follow. Pappas et al. (2014) have derived the GRR-1 source terms and dose results for three accident sequences under three distinct ventilation schemes. Out of the three studied accident sequences, namely the reactivity insertion accident, fuel channel blockage and LOCA, only the latter under normal ventilation and isolation (no-ventilation) produces doses beyond the maximum allowed annual effective dose $(1 \mathrm{mSv})$ to members of the public (Greek Government Gazette, 2001). Thus, the LOCA sequence under the two aforementioned ventilation schemes has been selected as hypothetical accident scenario for the present work.
The release path for the ventilation schemes is as follows: under normal ventilation the contaminated air is released to the environment solely through the reactor stack whereas the radionuclides escape from cracks/openings (ground release) under no-ventilation. The release has been assumed to last $24 \mathrm{~h}$ in accordance with the source term derivation of Pappas et al. (2014) while no iodine filtration has been employed in either of the two ventilation schemes. However, aerosols are filtered under normal ventilation. The resulting source terms appear in Figure 3 and the steps leading to their derivation can be found in Pappas et al. (2014). Overconservative assumptions have been made for the purpose of the Pappas et al. (2014) study. The outcome of that work has been employed in the current study and, as no uncertainties are estimated by JRODOS, the results presented are not associated with uncertainties.

Source term related parameters employed in JRODOS are: - a 24-h release period consisting of 24 hourly release intervals in accordance with the source term derivation;

- an air release rate of $5000 \mathrm{~m}^{3} \mathrm{~h}^{-1}$ at $50 \mathrm{~m}$ (stack release) and $100 \mathrm{~m}^{3} \mathrm{~h}^{-1}$ at $10 \mathrm{~m}$ (ground release) under normal ventilation and no-ventilation schemes, respectively;

- twenty five selected nuclides from the derived source terms, namely the noble gases ${ }^{85} \mathrm{Kr},{ }^{133,135} \mathrm{Xe}$, iodine isotopes ${ }^{131,135} \mathrm{I}$, as well as aerosols ${ }^{140} \mathrm{Ba},{ }^{141,143,144} \mathrm{Ce}$, 


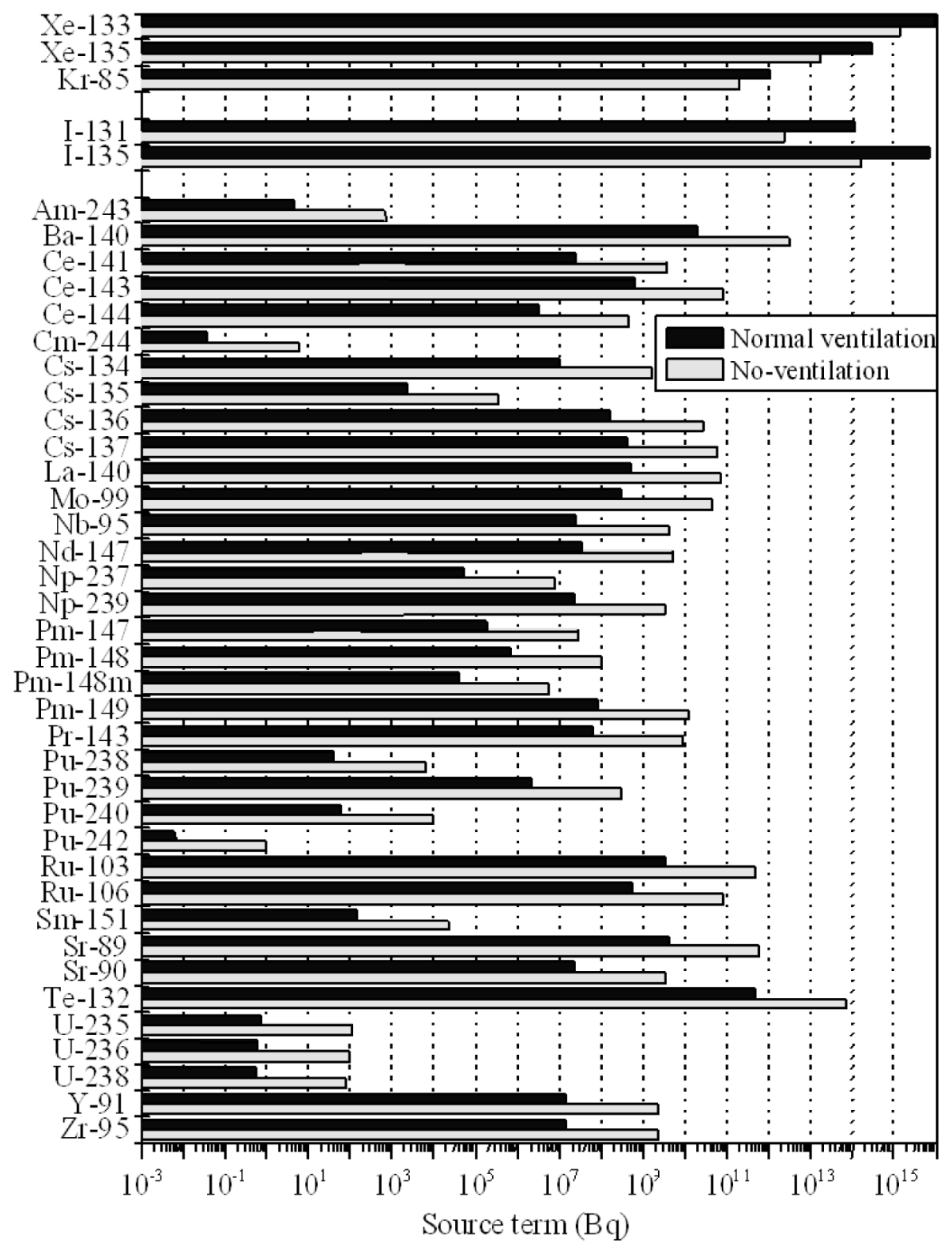

Fig. 3. 24-h source terms as a result of the LOCA under normal and no-ventilation schemes in GRR-1.

$$
\begin{aligned}
& { }^{134,136,137} \mathrm{Cs},{ }^{140} \mathrm{La},{ }^{99} \mathrm{Mo},{ }^{95} \mathrm{Nb},{ }^{147} \mathrm{Nd},{ }^{239} \mathrm{~Np},{ }^{143} \mathrm{Pr} \text {, } \\
& { }^{103,106} \mathrm{Ru},{ }^{89,90} \mathrm{Sr},{ }^{132} \mathrm{Te},{ }^{91} \mathrm{Y} \text { and }{ }^{95} \mathrm{Zr} \text {. }
\end{aligned}
$$

Meteorology plays a significant role in the source term dispersion and deposition. Rather than using the traditional approach where weather parameters are presumed constant throughout the duration of the analysis, the proposed approach is based on the identification of "typical weather patterns" which are selected from large scale reanalysis data sets and are used to feed downscaling numerical weather prediction models. The downscaled data closely approximates the meteorological conditions at the area of study accounting for spatial simulation of meteorological parameters and the dynamics of the atmosphere (Pinto et al., 2014).

In order to identify weather patterns that represent typical meteorological characteristics at the GRR-1 site the study of Sfetsos and Vlachogiannis (2010) has been utilized. It has
Table 1. WRF simulation domain.

\begin{tabular}{ll}
\hline Domain & Greece \\
\hline Spatial resolution & $3 \mathrm{~km}$ \\
Longwave radiation & $\begin{array}{l}\text { Rapid radiative transfer model general } \\
\text { (RRTMG) scheme }\end{array}$ \\
Shortwave radiation & RRTMG shortwave \\
Planetary boundary layer & Mellor-Yamada-Janjic \\
Surface-layer & Eta similarity \\
Microphysics & WRF single-moment 6-class scheme \\
Land-surface & Noah land surface model \\
Cumulus & Kain-Fritsch \\
\hline
\end{tabular}

employed a positive matrix factorization algorithm coupled with the $k$-means clustering algorithm over several years of measured meteorological data from five monitoring stations 


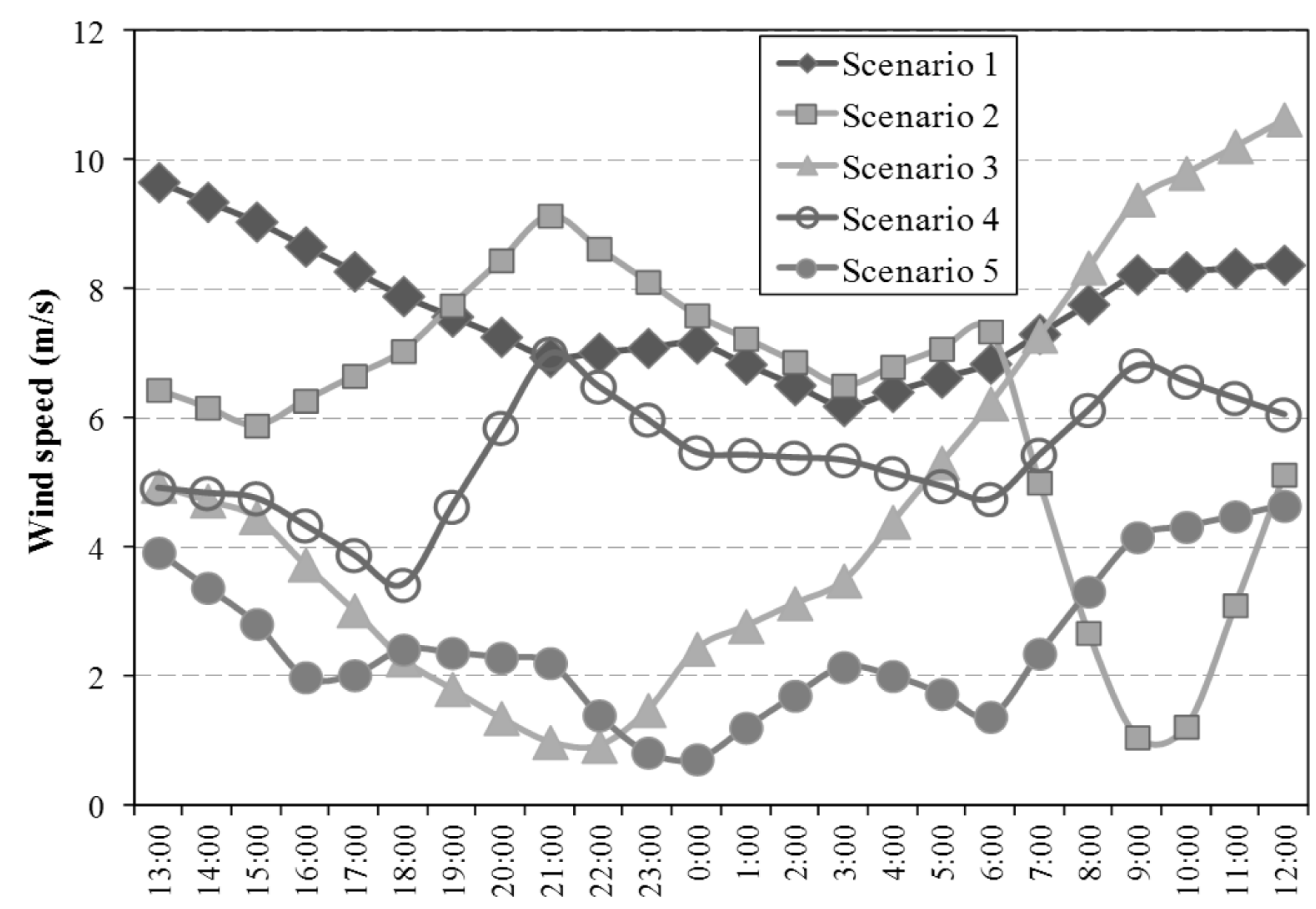

Time of day

Fig. 4. Wind speed (at $10 \mathrm{~m}$ height) at the reactor site during the radionuclide release for each weather scenario.

situated within the greater Athens area to identify distinct groups of dominant weather patterns that contribute to the appearance of increased particulate matter levels in the region of Attica, thus are considered to be the most probable ones to produce higher concentration levels. Five meteorological scenarios have emerged as representative of the annual weather conditions in Athens while a detailed description of the weather characteristics of each scenario may be found in Sfetsos and Vlachogiannis (2010). Each of the identified weather scenarios corresponds to a number of days that are characterized by circulation patterns and climate conditions pertaining to different temperature, wind and mixing layer height (MLH) than the other groups. The frequency of occurrence of these scenarios sums up to $98 \%$ of all possible weather scenarios, with scenario 4 presenting the greatest possibility to occur $(28 \%)$, followed by scenarios $3(27 \%), 2$ (15\%), $5(15 \%)$ and $1(13 \%)$.

The meteorological data from the above scenarios has been simulated with the mesoscale numerical weather prediction system Weather Research and Forecasting (WRF) v3.5 model (Skamarock et al., 2008) that has been set up using a simulation domain covering the Greek territory, and whose characteristics are listed in Table 1. The output of WRF was fed to the JRODOS Meteorological Pre-Processor (MPP) that is preconfigured and employs a 3-dimensional computational grid, Cartesian and uniform horizontally, extending to $200 \mathrm{~km}$ in both $\mathrm{W}-\mathrm{E}$ and $\mathrm{S}-\mathrm{N}$ directions, and non-uniform, terrainfollowing in the vertical direction, extending to $10 \mathrm{~km}$ in height (Andronopoulos et al., 2010). As a result, the JRODOS MPP scaled down the WRF data to a $2 \times 2 \mathrm{~km}^{2}$ horizontal resolution which is considered adequate for describing the topography effects on the wind flow in the particular area. It is noted that the JRODOS MPP includes a diagnostic wind flow module that adjusts the wind velocity vector to take into account the underlying topography while ensuring mass conservation. Figures 4-6 depict 24-h graphs of wind speed, wind direction and MLH as computed by the JRODOS MPP for the GRR-1 site and for each weather scenario (Figs. 4-6).

The simulations of the nuclide atmospheric dispersion were performed by the Lagrangian puff/particle dispersion model DIPCOT (DIsPersion over COmplex Terrain) which is integrated into JRODOS to simulate dispersion over complicated terrain such as the Greater Athens area where GRR-1 is located (Andronopoulos et al., 2010). DIPCOT utilizes fictitious puffs or particles assumed to move with the mean wind flow to which a random motion component is added to simulate turbulent diffusion. In the computations presented here, the Lagrangian puff mode of the model has been used. Gamma radiation dose rates in the air due to the radioactive plume are computed by a rapid method that takes into consideration the inhomogeneous 3-dimensional cloud shape (Andronopoulos et al., 2010). It is noted that the elevation difference between the stack and the nearest buildings as well as the sparse building configuration in the NCSR-D site allowed for neglecting the building wake effects in this study.

The following assumptions/definitions were made for the JRODOS computations presented in this paper:

- the release and prognosis in each scenario were initiated at 12:00 local time;

- the prognosis duration was set equal to $24 \mathrm{~h}$ starting at the beginning of the release. This duration was chosen as it simultaneously maximizes TEmersim while simulating countermeasures for the entire 24-h release phase;

- the computational domain (for dispersion, radiation doses and countermeasures) was defined as a $20 \times 20 \mathrm{~km}^{2}$ square centered on GRR-1 and discretized into square cells 


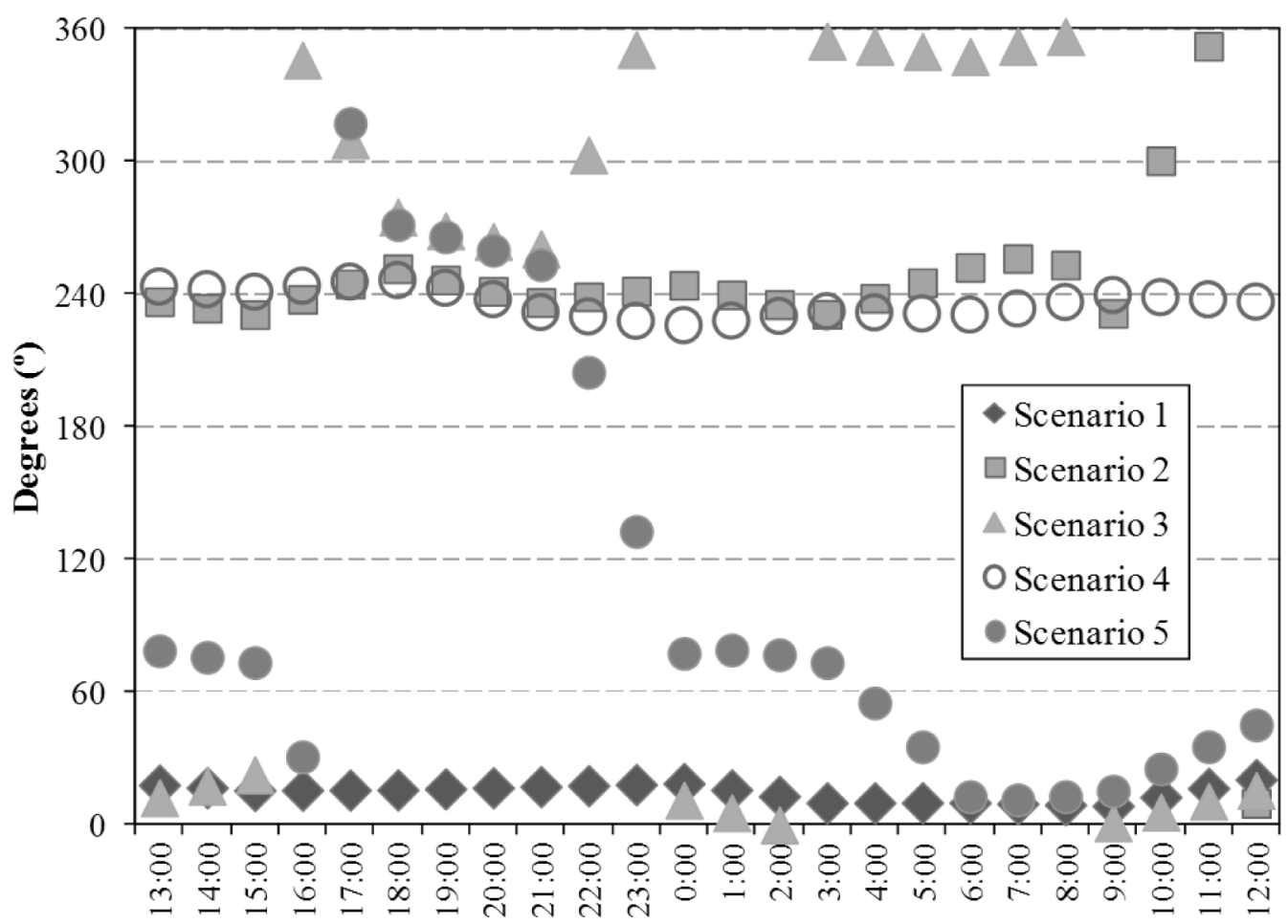

Time of day

Fig. 5. Wind direction (at $10 \mathrm{~m}$ height) at the reactor site during the radionuclide release for each weather scenario.

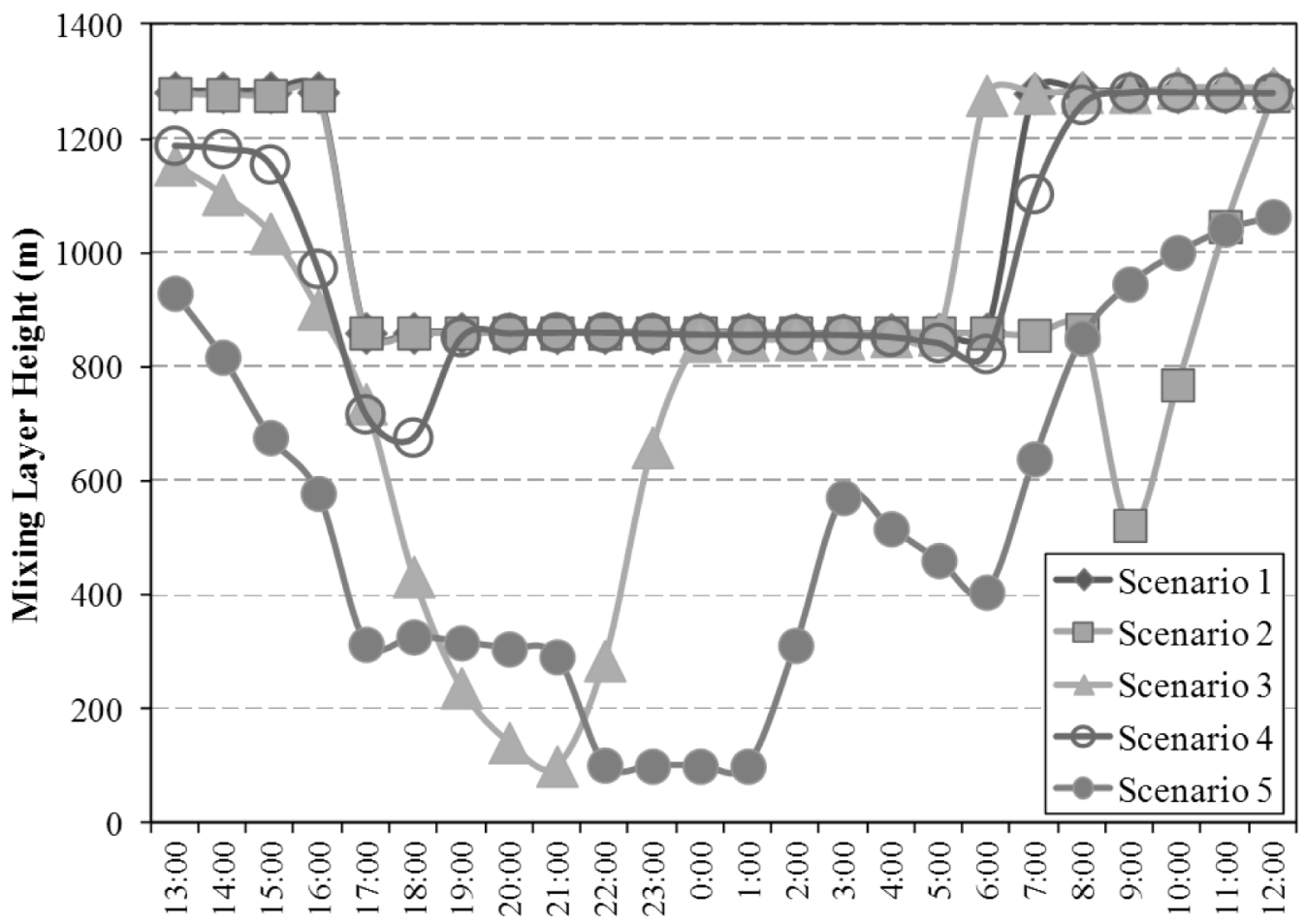

Time of day

Fig. 6. Mixing Layer Height at the reactor site during the radionuclide release for each weather scenario. 
Table 2. Early countermeasures intervention levels set in EMERSIM.

\begin{tabular}{lll}
\hline Countermeasure & Criterion dose and intervention levels & Dose type and simulation time \\
\hline $\begin{array}{l}\text { Sheltering } \\
\text { Evacuation }\end{array}$ & $\begin{array}{l}3 \mathrm{mSv} \text { effective dose and/or } 30 \mathrm{mSv} \\
\text { for either skin, lung or thyroid dose } \\
\begin{array}{l}30 \mathrm{mSv} \text { effective dose and/or } 300 \mathrm{mSv} \\
\text { for either skin, lung or thyroid dose }\end{array}\end{array}$ & $\begin{array}{l}\text { Gamma doses from inhalation, cloudshine and groundshine; 24h release } \\
\text { duration and } 49 \text { days simulation time; following cloud passage, only } \\
\text { groundshine is considered }\end{array}$ \\
$\begin{array}{l}\text { Intake of iodine } \\
\text { tablets }\end{array}$ & $30 \mathrm{mSv}$ committed dose & $\begin{array}{l}\text { Committed iodine inhalation dose to thyroid; 24h release duration and } \\
49 \text { days simulation time; following cloud passage, no dose is considered }\end{array}$ \\
$\begin{array}{l}\text { Temporary relocation } \\
\text { Permanent relocation }\end{array}$ & $30 \mathrm{mSv}$ effective dose & $\begin{array}{l}\text { Effective ground gamma dose; 24h release duration and 30 days } \\
\text { simulation time }\end{array}$ \\
& $100 \mathrm{mSv}$ effective dose & $\begin{array}{l}\text { Effective ground gamma dose; 24h release duration and 1 year } \\
\text { simulation time }\end{array}$ \\
\hline
\end{tabular}

that telescopically increase in size (from $50 \mathrm{~m}$ to $800 \mathrm{~m}$ ) when moving from the center towards the domain periphery.

The early countermeasures intervention levels as defined in EMERSIM cannot accurately simulate the intermediate areas in the Greek EPR plan, so they have been conservatively defined as the lower levels of NEP-X (cf. Fig. 2 and Tab. 2). As no time frame for calculation of the criterion dose is defined by NEP-X, a conservative approach has been adopted that maximizes the criterion dose with respect to the JRODOS limitations. In particular, the maximum scenario length of JRODOS (i.e. 49 days) has been employed as simulation time for the calculation of sheltering, evacuation and iodine intake criterion doses. It has also been assumed that sheltering actions start at the beginning of the release and last $24 \mathrm{~h}$ while iodine intake also takes place at the beginning of the release. The options for temporary and permanent relocation in EMERSIM are not addressed in NEP-X and the JRODOS default values (Päsler-Sauer, 2007) listed in Table 2 have been used in the present study.

\section{Results}

In total ten release scenarios have been studied comprising five weather cases for each of the two ventilation schemes. The spatial distribution of the effective gamma dose (from inhalation, cloudshine and groundshine), as computed by JRODOS at the end of the prognosis time following the LOCA sequence under normal ventilation for each weather scenario is depicted in Figure 7. It seems that the most adverse scenarios in terms of the effect on populated regions are scenarios 5 and 3 where the plume is headed mainly towards the city center and the southern suburbs, respectively. In scenario 1 the plume is headed S-SW reaching part of the eastern and southern suburbs of Athens. During scenarios 2 and 4 the plume is directed mostly E and NE away from densely populated regions. Similar dispersion patterns appear under no-ventilation. Maximum predicted values of the effective dose at the NCSR-D fence under both ventilation schemes are shown in Table 3. The LOCA sequence under no-ventilation produces lower overall doses as a result of lower iodine and noble gas releases. It should be noted that all results presented hereafter refer to members of the public outside NCSR-D since the
Table 3. Maximum estimated effective dose values at the NCSR-D fence for each accident sequence and weather scenario.

\begin{tabular}{|c|c|c|}
\hline \multirow[t]{2}{*}{$\begin{array}{l}\text { Weather } \\
\text { scenarios }\end{array}$} & \multicolumn{2}{|c|}{$\begin{array}{c}\text { Maximum effective dose }(\mathrm{mSv}) / \text { Distance } \\
\text { from reactor }(\mathrm{m})\end{array}$} \\
\hline & Normal ventilation & No-ventilation \\
\hline 1 & $11.1 / 400$ & $1.16 / 400$ \\
\hline 2 & $14.3 / 300$ & $2.26 / 300$ \\
\hline 3 & $21.1 / 300$ & $1.25 / 300$ \\
\hline 4 & $14.9 / 300$ & $1.81 / 300$ \\
\hline 5 & $4.6 / 800$ & $0.87 / 750$ \\
\hline
\end{tabular}

Table 4. Affected areas outside NCSR-D where sheltering actions are recommended for each weather scenario under normal ventilation.

\begin{tabular}{ll}
\hline Weather scenarios & Affected areas $\left(\mathrm{km}^{2}\right)$ \\
\hline 1 & 0.43 \\
2 & 0.34 \\
3 & 0.51 \\
4 & 0.36 \\
5 & 0.31 \\
\hline
\end{tabular}

study focused on off-site consequences in areas located more than $500 \mathrm{~m}$ from the stack. Concerning NCSR-D itself, a separate response plan exists in the case of a RN emergency, which has not been considered in the present study.

The JRODOS results show that no evacuation or relocation, temporary or permanent, is necessary in either of the examined scenarios. However, sheltering actions and intake of iodine tablets are suggested in certain occasions although to a very limited extent on the basis of the affected area.

Figure 8 presents the affected areas considered for sheltering actions during all weather scenarios following the LOCA sequence under normal ventilation. These areas extend no more than $1.5 \mathrm{~km}$ from the reactor building while they mainly involve forests surrounding NCSR-D and limited urban area outside it. In scenarios 1 and 3 the affected areas include forests south of NCSR-D and a section of the adjacent motorway that lies S-SE of the reactor building. Scenarios 2 and 4 refer to areas to the east of the reactor building at the mountain while covering only marginally inhabited areas and 

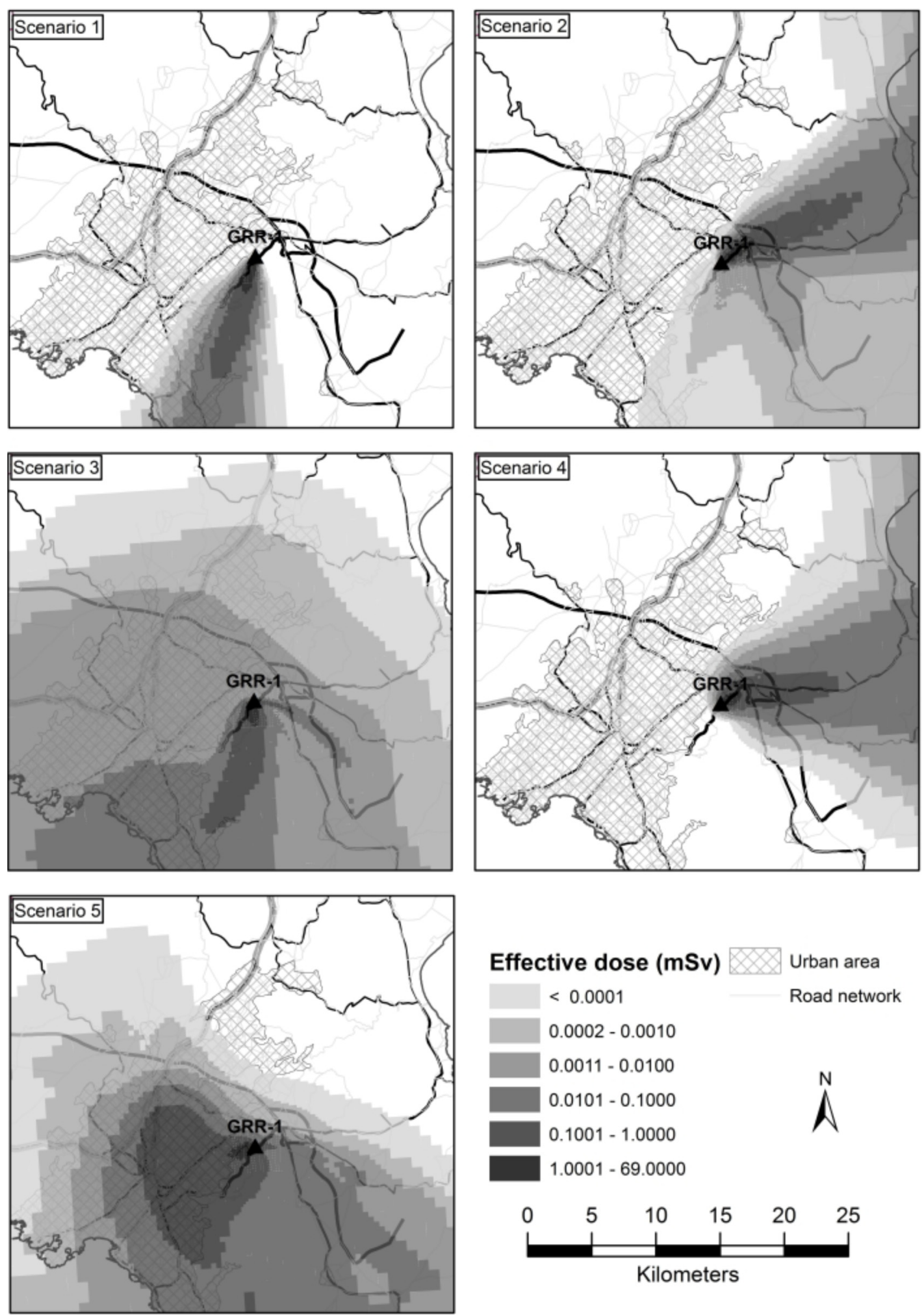

Fig. 7. Spatial distribution of the effective dose at the end of the 24-h period.

an educational facility located NE and the aforementioned motorway. The most adverse scenario under normal ventilation is scenario 5 where the involved area is located to the W-SW of the reactor building and covers a small part of the adjacent urban area. Table 4 lists the affected areas outside NCSR-D for each weather scenario. In practice sheltering in urban areas is either not suggested or suggested to a very limited extent. In the case of the LOCA sequence under no-ventilation the affected areas do not extend beyond NCSR-D and thus there are no areas requiring sheltering actions. 

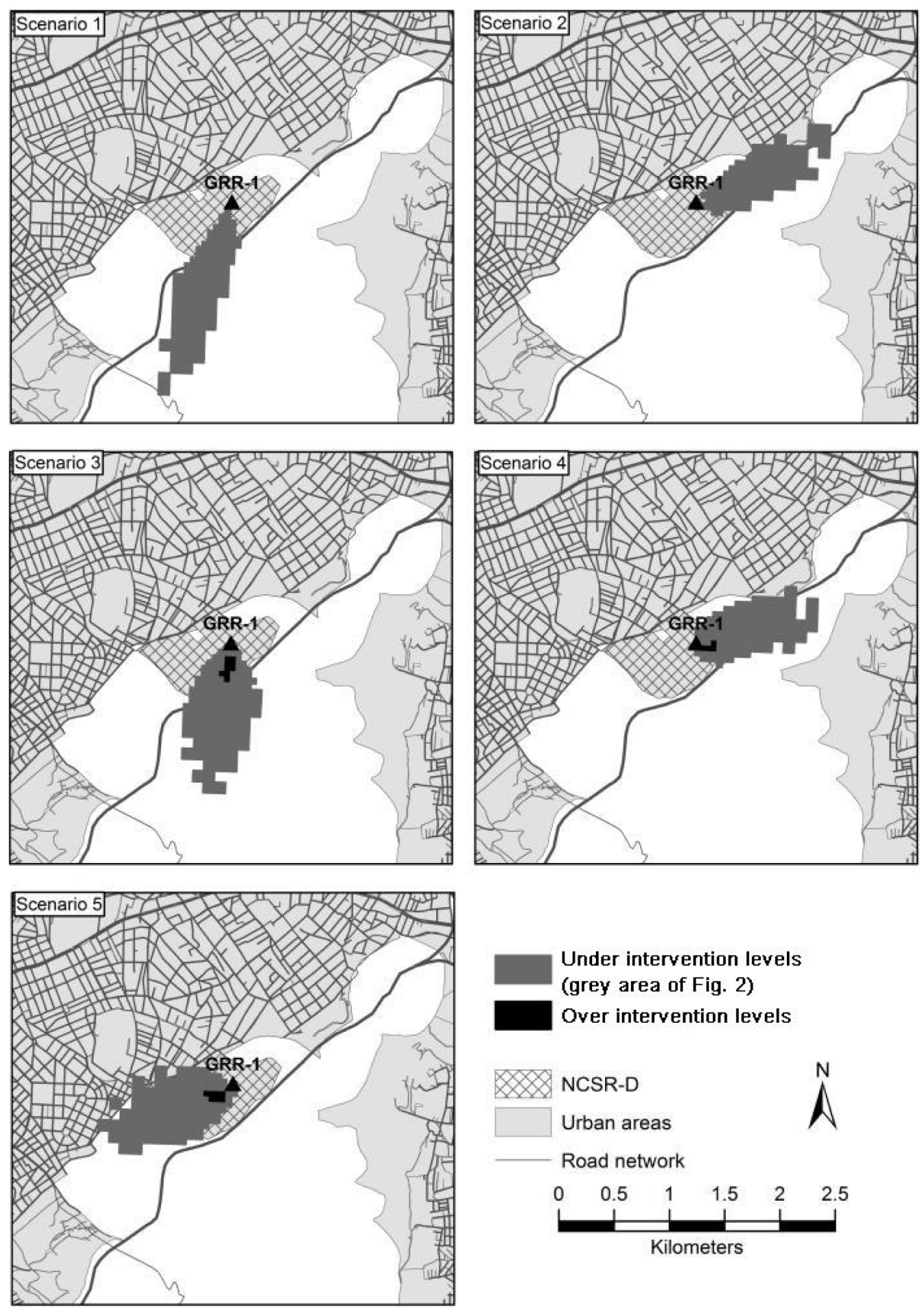

Under intervention levels

(grey area of Fig. 2)

Over intervention levels
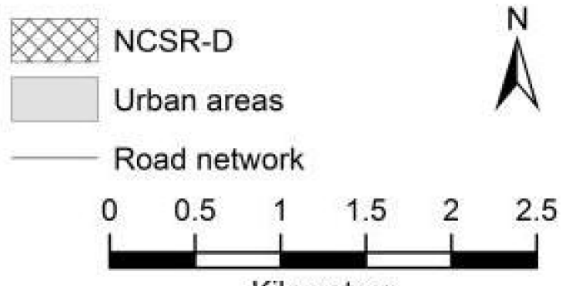

Kilometers

Fig. 8. Affected areas considered for sheltering actions for each weather scenario under normal ventilation.

Figures 9 and 10 delineate the affected areas where intake of iodine tablets is considered as a result of the LOCA under normal ventilation for children and adults, respectively. The affected areas outside NCSR-D are listed in Table 5 and range from 0.39 to $0.74 \mathrm{~km}^{2}$ and from 0.03 to $0.26 \mathrm{~km}^{2}$ as regards children and adults, respectively. The areas that refer to children are larger than those for adults for they are at higher risk at the same amount of iodine.

As regards children (Fig. 9), the affected area of scenario 2 includes an educational facility as well as some minor urban 

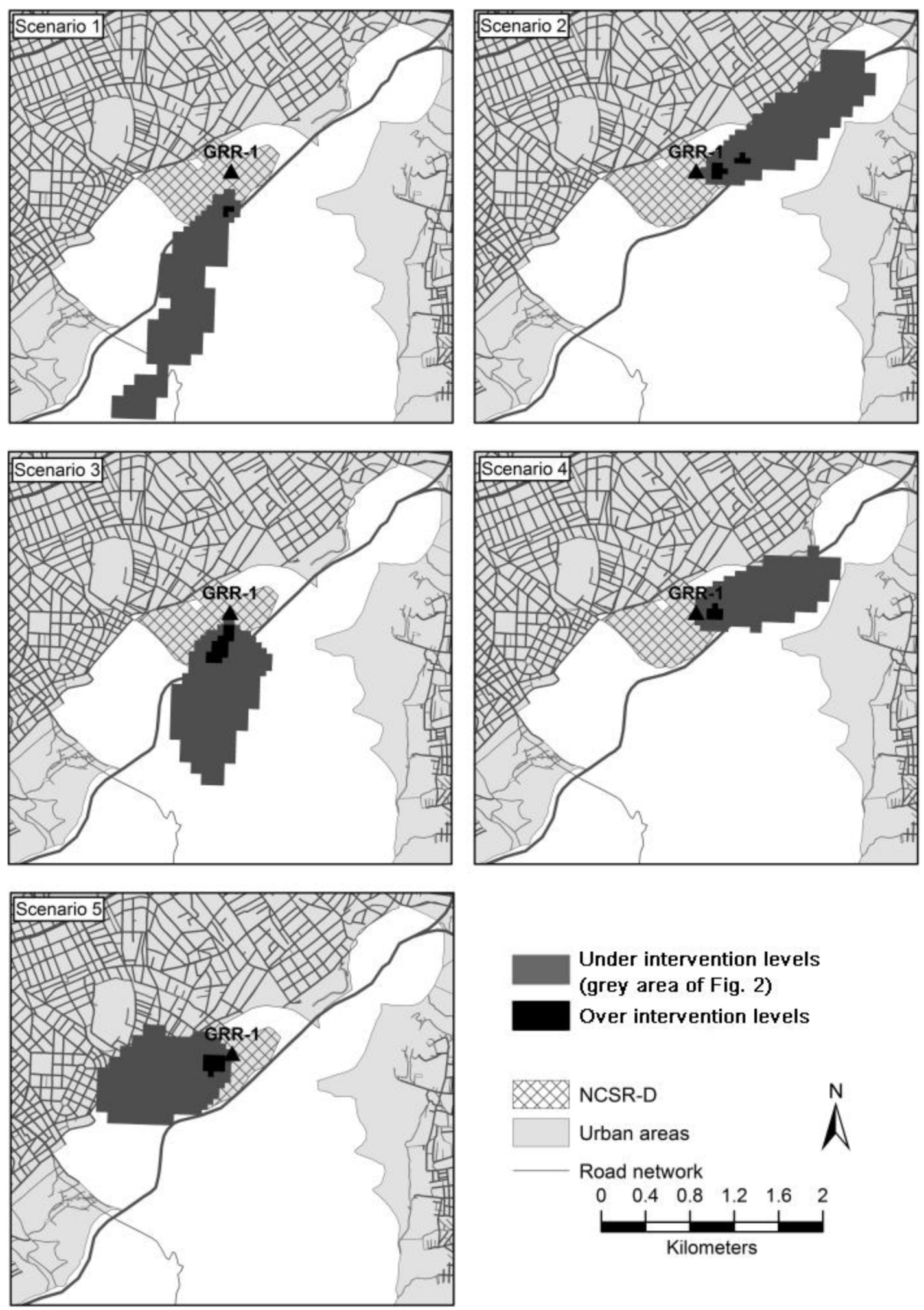

Fig. 9. Affected areas considered for iodine intake by children for each weather scenario under normal ventilation.

parts to the NE of the reactor building. Scenario 4 partly covers the aforementioned facility along with a small urban area to the $\mathrm{NE}$ whereas scenario 5 involves a small part of the adjacent urban area located to the west of the reactor building. Scenarios 1 and 3 affect forests to the south of the reactor building and part of the nearby motorway. When it comes to adults (Fig. 10) the affected areas are similar to the above described but smaller and they include very minor urban areas in scenarios 2 and 4 . Scenarios 1, 3 and 5 involve small non-urban areas S, S and SW of NCSR-D, respectively. 

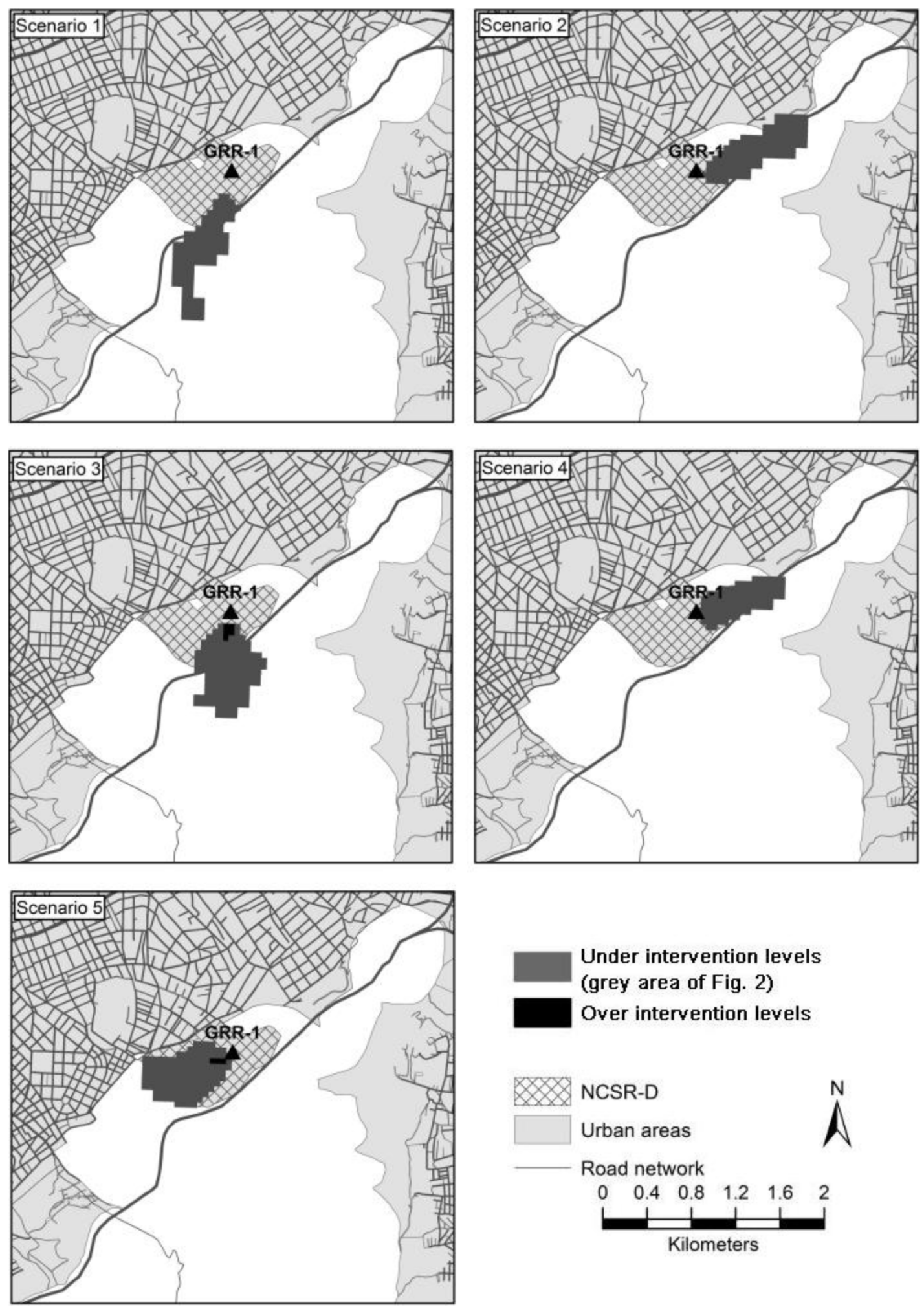

Fig. 10. Affected areas considered for iodine intake by adults for each weather scenario under normal ventilation.

As in sheltering, the affected areas estimated to receive doses larger than the NEP-X intervention levels (see Figs. 9 and 10) do not include urban areas whereas only scenarios 2,4 and 5 regarding children and scenarios 2 and 4 regarding adults include minor urban areas. Thus, iodine intake may be suggested, if at all, during these scenarios. Under noventilation the affected areas are limited within NCSR-D and, as a result, no iodine intake is recommended.

In order to quantify the effect of the aforementioned suggested countermeasures JRODOS simulates maximum 
Table 5. Affected areas outside NCSR-D where iodine intake is recommended for each weather scenario under normal ventilation.

\begin{tabular}{lll}
\hline $\begin{array}{l}\text { Weather } \\
\text { scenarios }\end{array}$ & $\begin{array}{l}\text { Iodine tablets to } \\
\text { adults }(12-45 \text { year) } \\
\text { Area }\left(\mathrm{km}^{2}\right)\end{array}$ & $\begin{array}{l}\text { Iodine tablets to } \\
\text { children (under 12 year) } \\
\text { Area }\left(\mathrm{km}^{2}\right)\end{array}$ \\
\hline 1 & 0.25 & 0.73 \\
2 & 0.24 & 0.74 \\
3 & 0.26 & 0.72 \\
4 & 0.14 & 0.54 \\
5 & 0.03 & 0.39 \\
\hline
\end{tabular}

Table 6. Effects of sheltering plus iodine tablet intake countermeasures at the NCSR-D fence, as estimated by JRODOS.

\begin{tabular}{llll}
\hline $\begin{array}{l}\text { Weather } \\
\text { scenarios }\end{array}$ & \multicolumn{2}{c}{$\begin{array}{c}\text { Maximum committed } \\
\text { effective dose without } \\
\text { countermeasures (mSv) }\end{array}$} & $\begin{array}{l}\text { Maximum committed } \\
\text { effective dose with } \\
\text { countermeasures: } \\
\text { sheltering + iodine } \\
\text { tablet intake (mSv) }\end{array}$ \\
\cline { 2 - 3 } Open air & $\begin{array}{l}\text { Normal } \\
\text { living }\end{array}$ & 4.58 \\
\hline 1 & 20.20 & 9.86 & 3.93 \\
3 & 14.60 & 7.48 & 3.90 \\
4 & 18.60 & 9.32 & 3.05 \\
5 & 12.80 & 5.70 & 1.39 \\
\hline
\end{tabular}

Table 7. Shielding factors employed by JRODOS for calculation of "open air" and "normal living" states.

\begin{tabular}{lll}
\hline Exposure type & \multicolumn{2}{c}{ Shielding factors } \\
\cline { 2 - 3 } & Open air & Normal living \\
\hline Groundshine & 1.0 & 0.208 \\
Cloudshine & 1.0 & 0.360 \\
Inhalation & 1.0 & 0.600 \\
\hline
\end{tabular}

doses received by members of the public with and without the application of countermeasures for selected time periods after the initiation of the release. Table 6 lists the maximum individual committed effective doses from cloudshine, groundshine and inhalation for each weather scenario integrated to the end of the 24-h period (after cloud passage only groundshine is considered). The doses have been computed at the NCSR-D fence in accordance with the direction of the plume. Thus, in scenarios $1-4$, the maximum doses correspond to forests $\mathrm{S}$ and $\mathrm{E}$ of the reactor and only in scenario 5 do the doses refer to urban area. In the case of no countermeasures two sets of dose data are generated: (a) "open air" that refer to potential doses (unshielded, in open air) and (b) doses assuming "normal living" inside buildings. The shielding factors employed for the calculations of "open air" and "normal living" are listed in Table 7 (Päsler-Sauer, 2007). It may be noted that there is uncertainty associated with the computations performed by a sequence of models in JRODOS and presented in Table 6. Thus, the dose reductions computed in percentages range from $45.9 \%$ to $58.2 \%$ and from $73.1 \%$ to $79.3 \%$ considering "normal living" and "open air" states, respectively. Therefore, the application of the proposed countermeasures is expected to have significant positive effects on members of the public in all examined scenarios.

\section{Conclusions}

The present paper has assessed early countermeasures for the public during a hypothetical radionuclide release by means of the JRODOS system. An overconservative LOCA sequence has been considered in a pool-type RR (GRR-1) located next to an urban area under two distinct ventilation schemes whereas five weather scenarios have been considered that represent typical meteorological conditions at the GRR-1 site. Therefore, ten release and dispersion scenarios have emerged. Countermeasures and intervention levels have been defined in accordance with the Greek legislation. Taking into account the limitations of the study, the results indicate that sheltering and iodine intake actions may be applied on limited urban areas surrounding GRR-1 during five release scenarios depending on the weather and the ventilation scheme. The effect of the proposed countermeasures to members of the public has been deemed positive by JRODOS as significant reductions of the maximum committed effective doses have been computed.

In the examined scenarios the proposed countermeasures have resulted from doses within the fuzzy area of the Greek EPR plan whereas doses exceeding the NEP-X intervention levels have been computed only in small areas inside NCSR-D rendering the application of the proposed countermeasures situation dependent. It may be concluded that despite assuming an overconservative LOCA sequence under adverse ventilation conditions, the recommended countermeasures are very limited, or nonexistent, during all examined weather scenarios.

Acknowledgments. The work leading to this publication has received funding from the European Commission DirectorateGeneral Home Affairs under contract HOME/2011/ISEC/AG/ CBRN/4000002163.

\section{References}

Andronopoulos S, Davakis E, Bartzis JG, Kovalets I. 2010. RODOS meteorological pre-processor and atmospheric dispersion model DIPCOT: a model suite for radionuclides dispersion in complex terrain. Radioprotection 45(5): S77-S84.

Charnock TW. 2010. The European model for inhabited areas (ERMIN) - developing a description of the urban environment. Radioprotection 45(5): S55-S61.

Gering F, Raskob W, Charnock T. 2010. New model for agricultural countermeasures in RODOS and ARGOS. Radioprotection 45(5): S63-S76.

Greek Government Gazette. 2001. Ministerial Decision No. 1014/ (FOR)94/2001. Approval of Radiation Protection Regulations. Government Gazette Folio No. 216/B/06.03.2001.

Greek Government Gazette. 2003. Ministerial Decision No. 1299/ 2003. Approval of the General Plan for Civil Protection, under the Code Name Xenokratis. Government Gazette Folio No. 423/B/ 10.04.2003. 
IAEA. 2002. Preparedness and response for a nuclear or radiological emergency. Vienna: IAEA Safety Standard Series, No. GS-R-2.

IAEA. 2007. IAEA safety glossary: terminology used in nuclear safety and radiation protection, 2007 Edition. Vienna: IAEA.

IAEA. 2011. Generic procedures for response to a nuclear or radiological emergency at research reactors. Vienna: IAEA-EPR.

Ievdin I, Tribushnyi D, Zheleznyak M, Raskob W. 2010. RODOS reengineering: aims and implementation details. Radioprotection 45(5): S181-S189.

Pappas C, Ikonomopoulos A, Sfetsos A, Andronopoulos S, Varvayanni M, Catsaros N. 2014. Derivation of the source term, dose results and associated radiological consequences for the Greek Research Reactor-1. Nucl. Eng. Des. 274: 100-117.
Päsler-Sauer J. 2007. Model description of the early countermeasures module EMERSIM in JRODOS PV 6.0 final. Report RODOS WG2_TN98_02. Denmark, Roskilde: RISO National Laboratory, $48 \mathrm{p}$.

Pinto JO, Monaghan AJ, Monache LD, Vanvyve E, Rife DL. 2014. Regional assessment of sampling techniques for more efficient dynamical climate downscaling. J. Clim. 27(4): 1524-1538.

Sfetsos A, Vlachogiannis D. 2010. A new approach to discovering the causal relationship between meteorological patterns and PM10 exceedances. Atmos. Res. 98: 500-511.

Skamarock WC, Klemp JB, Dudhia J, et al. 2008. A description of the advanced research WRF version 3. NCAR Technical Note. National Center for Atmospheric Research. http:/www2.mmm. ucar.edu/wrf/users/docs/arw_v3.pdf.

Cite this article as: Pappas C, Ikonomopoulos A, Sfetsos A, Andronopoulos S, Aneziris O, Varvayanni M, Catsaros N. 2017. Assessment of off-site early countermeasures in the event of a LOCA in a research reactor. Radioprotection 52(2): 87-99 